\title{
An Empirical Study of the Motivational Factors of Employees in Nigeria
}

\author{
Aworemi, Joshua Remi $P h D$ \\ Faculty of Management Science, Ladoke Akintola University of Technology, P.M.B. 4000 Ogbomoso, Nigeria
}

Tel: 234-080-3396-7307 E-mail: aworemi_remi@yahoo.com

Abdul-Azeez, Ibraheem Adegoke (corresponding author)
Department of Business Administration and Management Technology, Lagos State University, P.M.B. 0001, LASU
Post Office Ojo, Lagos, Nigeria

Tel: 234-070-3655-5582Ｅ-mail: ibforson@yahoo.com

Durowoju, Stella Toyosi
Department of Business Administration and Management Technology, Lagos State University, P.M.B. 0001, LASU
Post Office Ojo, Lagos, Nigeria

Tel: 234-080-3841-4213 E-mail: toyosiolugbon@yahoo.com

Received: April 8, 2011

Accepted: April 20, 2011

doi:10.5539/ijef.v3n5p227

\begin{abstract}
The objective of this research is to draw attention to the importance of certain factors in motivating employees in Nigeria. Specifically, the study sought to describe the ranked importance of the following seven motivating factors: (a) job security, (b) personal loyalty to employees, (c) interesting work, (d) good working conditions, (e) good wages, (f) promotions and growth in the organization, and (g) full appreciation of work done. The 15 companies selected from Oyo, Kwara, Osun and Ogun States of Nigeria are mid-sized companies that involved in Educational Consultancy, Hotel and Catering Services, Transportation services, Retail services and Manufacturing. Data were collected through a well-structured questionnaire delivered to the employees of the companies.

Findings of the study suggest that good working condition, interesting work, and good pay are key factors to higher employee motivation. Purposefully designed reward systems that include job enlargement, job enrichment, promotions, internal and external stipends, monetary, and non-monetary compensation should be considered. This will help the employer identify, recruit, employ, train, and retain a productive workforce.
\end{abstract}

Keywords: Employee, Factors, Motivation, Nigeria

\section{Introduction}

Motivation represents the forces within a person that affect his or her direction, intensity, and persistence of voluntary behavior (Pinder, 1998). Direction refers to the path along which people engage their effort. This sense of direction of effort reflects the fact that people have choices about where they put their effort. In other words, motivation is goal-directed, not random. People are motivated to arrive at work on time, finish a project a few hours early, or aim for many other targets. The second element of motivation, called intensity, is the amount of effort allocated to the goal. For example, two employees might be motivated to finish their project a few hour early (direction), but only one of them puts forth enough effort (intensity) to achieve this goal. In other words intensity is how much you push yourself to complete the task. Persistence which is the third element refers to the continuing the effort for a certain amount of time. Employees sustain their efforts until they reach their goals or give up beforehand.

Many studies have evolved around various motivational techniques for directing employees towards desired goals. However, the challenge to management is to recognize and understand the impact of various motivational systems on individual and group behaviour within an organised work endeavour. The success or failure of motivation rests not on the technique itself but on management's ability to match the needs of people with appropriate rewards" (Todes et al., 1977). Motives are needs, which force people to move towards goals, or point they define. Studies of motivation have tried to respond to the "why" of the human behaviour,which is directed towards a goal and the need for that goal. Hersey and Blanchard (1977) noted that mo-tives can be defined as needs, wants, drives, or impulses within the individual which are directed towards goals which may be conscious or subconscious. Freud long ago 
discovered the importance of subconscious motivation; in order words, people are not always aware of everything they want (Hersey and Blanchard, 1977). Dickson (1973) stated that employees are not motivated solely by money but by other factors, which is linked to their behaviour and attitudes.

The factors that can influence an individual's motivational processes at work have been categorized into two namely: Intrinsic and Extrinsic rewards. Intrinsic rewards are positive emotional experience resulting directly and naturally from the individual's behavior or results. This include the enjoyment of learning a new task, a feeling of accomplishment from performing a job well, and a sense of flow or engagement when work is performed smoothly. Extrinsic rewards on the other hand, are anything received from another person that the recipient values and is contingent on his or her behavior or results. Extrinsic rewards include paychecks, performance bonuses, praise, or some other form of recognition. Extrinsic rewards don't occur naturally with the behavior or result; instead someone introduces these rewards.

A survey of research findings on work motivation have generally suggested that intrinsic rewards are ranked as better motivators than extrinsic rewards (Kovach, 1987, Harpaz, 1990, and Lindner, 1998). The reason for this, however, is not farfetched. In the developed industrialized countries where majority of these researches are conducted, satisfaction of the basic needs of life such as food, shelter etc, are taken for granted by a large majority, hence emphasis has shifted from the extrinsic factors such as pay, incentives, promotion and so on, to intrinsic factors such as interesting work, achievement, recognition, challenge and self-actualization. The same, however, cannot be said for the less developed and developing world, such as Nigeria.

At one time, employees were considered just another input into the production of goods and services. What perhaps changed this way of thinking about employees was research, referred to as the Hawthorne Studies, conducted by Elton Mayo from 1924 to 1932 (Dickson, 1973). This study revealed that employees are not motivated solely by money and employee behavior is linked to their attitudes (Dickson, 1973). The Hawthorne Studies began the human relations approach to management, whereby the needs and motivation of employees become the primary focus of managers (Bedeian, 1993).

The objective of this research is to draw attention to the importance of certain factors in motivating employees in Nigeria. Specifically, the study sought to describe the ranked importance of the following seven motivating factors: (a) job security, (b) personal loyalty to employees, (c) interesting work, (d) good working conditions, (e) good wages, (f) promotions and growth in the organization, and (g) full appreciation of work done. A secondary purpose of the study was to compare the results of this study with the study results from other populations.

\section{Concept of Motivation}

Many contemporary authors have defined the concept of motivation. Motivation has been defined as the result of the interaction between the individual and the situation (Decenzo, 2001). Certainly, individuals differ in the motivational drive, but an individual's motivation varies from situation to situation, from culture to culture.

Lawler (1986) defined motivation as a conscious process that results from individual choice about what will and will not be in a given situation. Kreitner (1995) defined the phenomenon as a psychological process that gives behavior purpose and direction. . Motivation has been defined as: a predisposition to behave in a purposive manner to achieve specific, unmet needs (Buford, Bedeian \& Lindner, 1995); an internal drive to satisfy an unsatisfied need (Higgins, 1994); and the will to achieve (Bedeian, 1993). For this paper, motivation is operationally defined as the inner force that drives individuals to accomplish personal and organizational goals.

\section{Theories of Motivation}

Motivation theories are classified into two groups; content theories and process theories (Iguisi, 2009). Content theories explore what motivate people, that is arouses and energized the behavior. The most famous content theories are Maslow's need hierarchy, Herzberg's two-factor theory and McCelland's three-factor theory. Process theories researched the specifics of the motivation process. Vroom's expectancy theory, Four-drive theory, Skinner's reinforcement theory and Adam's equity theory are well known process theories. Among motivation theories to be reviewed are those of Maslow, McClelland, Vroom, and Lawrence and Nohria.

\subsection{Maslow's Needs Hierarchy Theory}

Maslow's need hierarchy theory was developed by Psychologist Abraham Maslow in the 1940s. The model has been applied in almost every human pursuit, from marketing products to rehabilitating prison inmates. This incredible popularity is rather odd considering that the theory has little research support.

Maslow's need hierarchy organizes dozen of different needs into five basic categories arranged in the hierarchy. Physiological needs (for food, air, water, shelter, and the like) are at the bottom of the hierarchy. Next are safety 
needs - the need for a secure and stable environment and the absence of pain, threat, or illness. Belongingness includes the need for love, affection, and interaction with other people. Esteem includes self-esteem through personal achievement as well as social esteem through recognition and respect from others. At the top of the hierarchy is self-actualization, which represents the need for self-fulfillment - a sense that one's potential has been realized. In addition to these five, Maslow describes the need to know and need for aesthetic beauty as two needs that do not fit within the hierarchy.

Needs hierarchy theory says that people are motivated by several needs at the same time, but the strongest source is the lowest unsatisfied need. As the person satisfies a lower-level need, the next higher need in the hierarchy becomes the primary motivator and remains so even if never satisfied. Physiological needs are initially the most important, and people are motivated to satisfy them first. As they become gratified, safety needs emerge as the strongest motivator. As safety needs are satisfied, belongingness needs become most important, and so forth. The exception to this fulfillment process is self-actualization; as people experience self-actualization, they desire more rather than less of this gratification. Thus while the bottom four groups are deficiency needs because they become activated when unfulfilled, self actualization is known as a growth need because it continues to develop even when fulfilled.

However, the most serious limitation of Maslow's needs hierarchy is its assumption that everyone has the same needs hierarchy. Research has revealed that this is a false assumption. People actually have different needs hierarchies tied to their personal values. Needs are conscious deficiencies produced from innate drives but strengthened or weakened through learning and social forces such as culture and childhood upbringing. Furthermore, studies have reported that the general needs hierarchy in some cultures is different from the needs hierarchy in other cultures (Oishi et al, 1999).

\subsection{McClelland Learned Needs Theory}

David McClelland, a psychologist some decades ago expanded on Maslow's idea that need strength is reinforced or weakened by personal values and social influences (culture, norms, and so on). Specifically, McClelland suggested that need strength is reinforced through childhood learning, parental style, and social norms. He paid attention to three learned needs: achievement, power and affiliation (McClelland, 1961).

Need for achievement (nAch): people with a strong need for achievement (nAch) want to accomplish reasonably challenging goals through their own efforts. They prefer working alone rather than in teams, and they choose tasks with a moderate degree of risk (neither too easy nor impossible to complete). High nAch people also desire unambiguous feedback and recognition for their success. Successful entrepreneurs tend to have a high nAch. Need for affiliation (nAff): need for affiliation refers to a desire to seek approval from others, conform to their wishes and expectations, and avoid conflict and confrontation. People with a strong nAff try to project a favourable image of themselves and tend to actively support others and try to smooth out workplace conflicts.

Need for power (nPow): people with high need for power (nPow) want to exercise control over others and are concerned about maintaining their leadership positions. Those who enjoy their power to advance personal interests have personalised power. Others mainly have a high need for socialized power because they desire power as a means to help others. Effective leaders have a high need for socialized rather than personalized power.

McClelland learned needs theory repeat the point that a person's needs can be strengthened or weakened with experience (reinforcement) and social influences. The lesson here is that managers can strengthen or weaken employees need for achievement, power, and affiliation, such as by supporting an achievement-oriented culture, rewarding those who demonstrate achievement orientation, and hiring co-workers who developed a strong achievement orientation in their upbringing.

\subsection{Vroom Expectancy Theory}

Vroom approaches the issue of human motivation quite differently from the ways Maslow and Herzberg did (Vroom 1964). He holds that people will be motivated to pursue the achievement of a desired goal if: (i) they believe in the worth of the goal; and (ii) they believe that their actions will ensure the attainment of the goal. In a more detailed form, Vroom believe that a person's motivation to perform will depend on the value the person places on the outcome of his efforts multiplied by his confidence that the efforts will actually help to desired goal; that is $\mathrm{F}=\mathrm{V} \times$ E. Vroom's theory shows that individuals' have goals and are motivated towards actions that will ensure the achievement of these goals. As such, managers should communicate how employees goals, such as promotion, more pay, recognition, and so on, can be earned in terms of what behavioral patterns are known to employees, such patterns should form the basis for administering rewards. Otherwise problems will occur in terms of workers' lack of confidence in organizational policy, and the result may be detrimental to good working environment. 


\subsection{Four-Drive Theory}

Four-drive theory, which was recently introduced by Harvard Business School professors Paul Lawrence and Nitin Nohria, captures many of these recent discoveries (Lawrence \& Nohria, 2002). Based on their review of existing research, they identified four drives that seem to apply to everyone:

Drive to acquire: this is the drive to seek, take, control and retain objects and personal experiences. The drive to acquire extends beyond basic food and water; it includes the need for relative status and recognition in society. Thus it is the foundation of competition and the basis of our need for esteem.

Drive for bond: this is the drive to form social relationships and develop mutual caring commitments with others. Research indicates that people invest considerable time and effort in forming and maintaining relationships without any special circumstances or ulterior motives (Baumeister \& Leary, 1995). The drive to bond motivates people to cooperate and consequently is a fundamental ingredient in the success of organizations and the development of societies.

Drive to defend: this drive creates a "fight-or-flight" response in the face of personal danger. The drive to defend goes beyond protecting our physical self. It includes defending our relationships, our acquisitions, and our belief systems. The drive to defend is always reactive-it is triggered by threat. In contrast, the other three drives are always proactive-we actively seek to improve our acquisitions, relationships, and knowledge.

Basically, our brain uses these four drives to quickly evaluate and assign emotions to information received through our senses. Suppose you learn that your boss has been promoted and an outsider has been hired to fill the vacant position. This sort of event likely triggers both the emotions of worry and curiosity. The drive to defend generates your worry about how the new manager will affect your comfortable work routine, whereas the drive to learn generates curiosity about what the new boss looks and acts like. The key point here is that the four innate drives determine which emotions triggered in each situation (Hill \& McShane, 2008).

\section{Benefits of Motivation}

Motivation is a very important for an organization because of the following benefits it provides:-

\subsection{Puts human resources into action}

Every concern requires physical, financial and human resources to accomplish the goals. It is through motivation that the human resources can be utilized by making full use of it. This can be done by building willingness in employees to work. This will help the enterprise in securing best possible utilization of resources.

\subsection{Improves level of efficiency of employees}

The level of a subordinate or a employee does not only depend upon his qualifications and abilities. For getting best of his work performance, the gap between ability and willingness has to be filled which helps in improving the level of performance of subordinates. This will result into-

Increase in productivity,

Reducing cost of operations, and

Improving overall efficiency.

\subsection{Leads to achievement of organizational goals}

The goals of an enterprise can be achieved only when the following factors take place :-

There is best possible utilization of resources,

There is a co-operative work environment,

The employees are goal-directed and they act in a purposive manner,

Goals can be achieved if co-ordination and co-operation takes place simultaneously which can be effectively done through motivation.

\subsection{Builds friendly relationship}

Motivation is an important factor which brings employees satisfaction. This can be done by keeping into mind and framing an incentive plan for the benefit of the employees. This could initiate the following things:

Monetary and non-monetary incentives,

Promotion opportunities for employees,

Disincentives for inefficient employees.

Effective co-operation which brings stability, 
Industrial dispute and unrest in employees will reduce,

The employees will be adaptable to the changes and there will be no resistance to the change,

This will help in providing a smooth and sound concern in which individual interests will coincide with the organizational interests,

This will result in profit maximization through increased productivity.

\subsection{Leads to stability of work force}

Stability of workforce is very important from the point of view of reputation and goodwill of a concern. The employees can remain loyal to the enterprise only when they have a feeling of participation in the management. The skills and efficiency of employees will always be of advantage to employees as well as employees. This will lead to a good public image in the market which will attract competent and qualified people into a concern. As it is said, "Old is gold" which suffices with the role of motivation here, the older the people, more the experience and their adjustment into a concern which can be of benefit to the enterprise.

\section{Methodology}

The research design for this study employed a descriptive survey method. The target population of this study included all the employees of 15 randomly selected companies from Oyo, Kwara, Osun and Ogun States of Nigeria. The sample size included 300 randomly selected employees of the target population i.e. twenty employees from each company. Two hundred and Eighty questionnaires were found analyzable out of the 300 questionnaires sent out for the survey given the participation rate of 93.3\%. The companies are into Educational Consultancy, Hotel and Catering Services, Transportation services, Retail services and Manufacturing. These companies were basically chosen because of their diverse and rich workforce. They also have good reputation in employees' motivation.

Data were collected through the use of a written questionnaire hand-delivered to the participants. Questionnaires were filled out by participants and returned to the researchers. The questionnaire asked participants to express their agreement with the seven motivational factors in a Likert-type scale. The options are strongly agreed, partially agreed and not agreed. The result of the agreement was later ranked according to their importance that is $1=$ strongly agreed, $0.5=$ partially agreed and $0=$ not agreed. The instrument was pilot tested with three similarly situated employees within the selected states. As a result of the pilot test, minor changes in word selection and instructions were made to the questionnaire.

The motivational factors are (a) job security, (b) personal loyalty to employees, (c) interesting work, (d) good working conditions, (g) good wages, (h) promotions and growth in the organization, and (j) full appreciation of work done.

\section{Results and Discussion}

The ranked order of the motivating factors according to the respondents are; (a) Good working conditions, (b) interesting work, (c) good wages, (d) job security, (e) promotion and growth in the organization, (f) full appreciation of work done, (g) personal loyalty to employees.

From Table 1, Good working condition was considered as the best motivator by the employees. This is due to the fact that when the environment is conducive for working, people tend to bring out the best in them. Good working condition include good physical conditions (such as good ventilation, adequate workplace, lighting), good working relationship with the superior, little tension on the job, and freedom to adopt your own approach, just to mention a few. This observation is in line with the Maslow's needs hierarchy because good working condition is a self-actualizing factor.

Interesting Work is ranked second by the respondents and it is also considered as self-actualizing factor going by the Maslow's hierarchy of needs. Two hundred and fifty one respondents (89.6\%) strongly agreed to the fact that they are motivated when doing an interesting work, while the remaining $29(10.4 \%)$ partially agreed. This result corroborates the Vroom's expectancy theory in the sense that when an employee is doing what he enjoys he/she will devote much effort to it which will lead to performance and high performance will lead to positive reward. The more positive the reward the more likely the employee will be highly motivated.

Good wages was ranked as third motivator by the respondents. Two hundred and thirty two respondents (82.9\%) strongly agreed that good wages enhance their performance while the remaining 48 respondents (17.1\%) partially agreed. Further analysis of the good wage system shows that regular payment of salaries and leave bonus, transport and housing allowance, annual salary increment, meal subsidy, and regular promotion opportunities are very crucial and important in motivating employees. This study corroborates the finding of Popoola (1982), Ekerete (2001), 
Ekhator (2003) that Nigerian worker have a high aspiration for money and wealth and is only motivated to perform by financial incentives.

Job security was seen as one of the motivational factors by $75 \%$ of the respondents as shown in Table 1 . Ranked fourth by the respondents, it covers both physical and emotional security and is in the second level of needs in Maslow's hierarchy. It includes the need for reasonable freedom from fear pain or threat, personal safety, work security, economic maintenance, emotional stability, the need for predictability and orderliness. Promotion and growth in the organization was ranked fifth by the respondents and it was agreed by $70 \%$ that it is a good motivator.

The sixth ranked factor of motivation according to Table 1 is full appreciation of work done and it was strongly agreed by the majority of respondents that it motivates them to do more. This factor can be compared to Adam's equity theory. If an employee of a company feels that there is a lack of appreciation for work done, as being too low relative to another employee, an inequity may exist and the employee will be dis-motivated. Adam (1965) stated that employees will attempt to restore equity through various means, some of which may be counter-productive to organizational goals and objectives. Personal loyalty to employees by the employer was ranked least by the respondents as one of the factors that motivate employees. One hundred and sixty three respondents representing $58.2 \%$ strongly agreed, $34.6 \%$ partially agreed while the remaining $7.2 \%$ disagreed.

The overall analysis of the motivational factors as it relates to the employees of the selected companies in Nigeria shows that $76.3 \%$ of the employees strongly agreed to the fact that all the factors motivate them to contribute immensely to the growth and development of the companies while $21.6 \%$ and $2.1 \%$ agreed partially and disagreed respectively.

Comparing the outcome of the ranking in this research with other related research provides some interesting insight into employee motivation. A study of industrial employees conducted by Kovach (1987), yielded the following ranked order of motivational factors (a) interesting work, (b) full appreciation of work done, (c) feeling of being in on things. Another study of employees conducted by Lindner (1998), yielded the following ranked order of motivational factors (a) interesting work, (b) good wages, and (c) full appreciation of work done.

In this study and the two cited above, interesting work ranked as one of the most important motivational factor. Pay was not ranked as one of the most important motivational factors by Kovach (1987), but was ranked third in this research and second by Lindner (1998). Good working condition was not ranked as one of the most important motivational factors by Kovach (1987) and Lindner (1998), but was ranked first in this research. The difference in ranked order in these research findings shows that what motivates employees differs from time to time and from organization to organization given the context in which employee works. What can be generalized however, in these studies is that interesting work and good pay are very important motivational factors for employees.

\section{Conclusion and Recommendations}

This study has confirmed the importance of motivational factors in getting the best from the employees. It has also revealed, through the ranking, the order at which all these factors motivates the employees. It also provides useful information for the managers and employees. Knowing how to use this information in motivating employees is complex. The strategy for motivating employees depends on which motivation theories are used as a reference point. If Hertzberg's theory is followed, management should begin by focusing on pay and job security (hygiene factors) before focusing on good working condition and interesting job (motivator factors). If Lawrence and Nohria's four-drive theory is followed, management should begin by focusing on area where there would be a balanced opportunity to fulfil the drives to acquire, bond, learn, and defend. Good working condition, good pay, job security, and promotion and growth in the organization should be the starting point. If McClelland's theory is followed, management should paid attention to the needs for achievement, affiliation and power by the employees.

Regardless of which theory is followed, good working condition, interesting wok, and employee pay appear to be important links to higher motivation of employees according to the findings of this study. Options such as job enlargement, job enrichment, promotions, internal and external stipends, monetary, and non-monetary compensation should also be considered. The key to motivating employees is to know what motivates them and designing a motivation program based on those needs.

Lastly, this study however recommends that employers should endeavour to know what motivates their employees and incorporate them into the reward system. This will help the employer identify, recruit, employ, train, and retain a productive workforce.

\section{References}

Adams, J. S. (1965). Inequity in social exchange, In L. Berkowitz (ed.). Advances in experimental social psychology. New York: Academic Press. 
Baumeister R. E. \& Leary M. R .(1995). The need to belong: desire for interpersonal attachments as a fundamental human motivation, Psychological Bulletin, 117, pp 497-529. doi:10.1037/0033-2909.117.3.497, http://dx.doi.org/10.1037/0033-2909.117.3.497

Bedeian, A. G. (1993). Management (3rd ed.). New York: Dryden Press.

Buford, J. A., Jr., Bedeian, A. G., \& Lindner, J. R. (1995). Management in Extension (3rd ed.) Columbus, Ohio: Ohio State University Extension.

Decenzo D. A. (2001). Fundamentals of Management: Essentials Concepts and Application, Prentice Hall, New Jersey

Dickson, W. J. (1973). Hawthorne experiments. In C. Heyel (ed.). The encyclopedia of management, 2nd ed. (pp. 298-302). New York: Van Nostrand Reinhold.

Ekerete, P. P. (2001). Sales Force Motivation Strategies in Some Selected Industries in Nigeria: A Comparative Study" International Journal of Economic and Development Issues 5(1): $104-115$.

Ekhator, V. E. (2003). Problems and Prospects of Staff in the Civil Service, Advances in Management, 3(1): 9 - 17.

Harpaz, I. (1990). The importance of work goals: an international perspective, Journal of International Business Studies, 21, 75-93. doi:10.1057/palgrave.jibs.8490328, http://dx.doi.org/10.1057/palgrave.jibs.8490328

Hersey P., \& Blanchard K. (1977). Management of Organisational Behaviour, Englewood Cliffs: Prentice Hall.

Hill, C. W. \& McShane, S. L. (2008). Principles of Management, New York, McGraw-Hill, Irwin

Iguisi O. (2009). Motivation-related values across cultures, African Journal of Business Management, Vol. 3(4) pp $141-150$.

Kovach, K. A. (1987). What motivates employees? Workers and supervisors give different answers, Business Horizons, 30, 58-65. doi:10.1016/0007-6813(87)90082-6, http://dx.doi.org/10.1016/0007-6813(87)90082-6

Kreitner, R. (1995). Management (6th ed.). Boston: Houghton Mifflin Company.

Lawler, E. E. (1986). High Involvement Management: Participative Strategies for Improved Organizational Performance. San-Francisco, Jossey - Bass, California.

Lawrence P. R. \& Nohria N. (2002). Driven: how human nature shapes our choices, San Francisco. Jossey-Bass.

Lindner, J. R. (1998), “Understanding Employee Motivation”, Journal of Extension 36(3)

Maslow, A. H. (1943). A theory of human motivation, Psychological Review, 50, 370-396. doi:10.1037/h0054346, http://dx.doi.org/10.1037/h0054346

McClelland D. (1961). The Achieving Society, Princeton NJ, van Nostrand

Oishi, S. (1999). Cross-cultural variations in predictors of life satisfaction: perspectives from Needs and Values, Personality and Social Psychological Bulletin 25, no 8 pp 980-990. doi:10.1177/01461672992511006, http://dx.doi.org/10.1177/01461672992511006

Pinder C. C. (1998). Work motivation in organizational Behavior, Upper saddle River, NJ, Prentice Hall

Popoola, D. (1982). Job Satisfaction in Institution of Higher Learning: The University of Lagos Experience, Nigerian Journal of Education and Development. 5(1), pp 115-125

Todes J. L., McKinney, J. \& Ferguson W. Jr. (1977). Management and Motivation, New York: Harper and Row.

Vroom, V. H. (1964). Work and motivation, New York: Wiley.

Table 1. Ranking of the Motivational factors

\begin{tabular}{lllllll}
\hline Motivational factors & $\begin{array}{c}\text { Strongly } \\
\text { Agreed }\end{array}$ & $\begin{array}{l}\text { Partially } \\
\text { Agreed }\end{array}$ & $\begin{array}{l}\text { Not } \\
\text { Agreed }\end{array}$ & Total & $\begin{array}{l}\text { Score } \\
\text { Total }\end{array}$ & Rank \\
\hline Interesting Work & 251 & 29 & 0 & 280 & 265.5 & 2 \\
Job Security & 210 & 70 & 0 & 280 & 245 & 4 \\
Good Wages & 232 & 48 & 0 & 280 & 256 & 3 \\
Good working Condition & 266 & 14 & 0 & 280 & 273 & 1 \\
Promotion and Growth in the Organization & 196 & 84 & 0 & 280 & 238 & 5 \\
Personal loyalty to employees & 163 & 97 & 20 & 280 & 211.5 & 7 \\
Full appreciation of work done & 177 & 81 & 22 & 280 & 217.5 & 6 \\
TOTAL & $1495(76.3 \%)$ & $423(21.6 \%)$ & $42(2.1 \%)$ & 1960 & & \\
\hline
\end{tabular}

Source: Authors' field survey, 2009 